\title{
Review: antidepressants and psychotherapy may be equally effective for promoting remission in major depressive disorder
}

\author{
Casacalenda N, Perry C, Looper K. Remission in major depressive disorder: a comparison of pharmacotherapy, \\ psychotherapy, and control conditions. Am J Psych 2002 Aug; 159:1354-60. \\ Institute of Community \\ and Family Psychiatry, \\ Jewish General \\ Hospital, Montreal, \\ Canada. \\ ncasacal@ \\ icfp.jgh.mcgill.ca

\section{QUESTION: How do anti-depressants and psychotherapy compare in generating full remission in major depressive disorder?}

Source of funding:
None specified.

For correspondence: N Casacalenda,

\section{Design}

Systematic review with meta-analysis.

\section{Data sources}

Studies were identified using Medline and PsychInfo (to November 2000).

\section{Study selection}

Eligible studies were randomised controlled trials with blinded participants and assessors that (1) directly compared medications, psychotherapy and controls for well defined major depressive disorder; (2) included remission data. 6 studies were included with 883 outpatients with mild to moderate non-psychotic major depressive disorder. Mean age ranged from 32-40 years; $77 \%$ women (range $68-85 \%$ ). Median treatment duration was 16 weeks (range 10-34).

\section{Data extraction}

Data were extracted on baseline measurements, sample size, duration of treatment, remission, follow up and dropout rates. The main outcome was full remission.

\section{Main results}

Tricyclic antidepressants, phenelzine and psychotherapy (primarily cognitive behaviour and interpersonal therapies) were more effective at promoting remission than control conditions. There was no difference in remission between antidepressants and psychotherapy regimens (table).

\section{Conclusions}

Antidepressants and psychotherapy may both be effective first-line treatments for outpatients with mild to moderate depression.

Outcomes for people with mild to moderate depression receiving pharmacotherapy, psychotherapy or control conditions

\begin{tabular}{lccc} 
Outcome & $\begin{array}{c}\text { Pharmacotherapy } \\
\%(n=261)\end{array}$ & $\begin{array}{c}\text { Psychotherapy } \\
\%(n=352)\end{array}$ & $\begin{array}{c}\text { Control } \\
\%(n=270)\end{array}$ \\
$\begin{array}{l}\text { Full } \\
\text { remission }\end{array}$ & 46.4 & 46.3 & 24.4 \\
\hline $\begin{array}{l}\text { Treatment } \\
\text { dropout }\end{array}$ & 37.1 & 22.2 & 54.4 \\
\hline
\end{tabular}

Note: For remission, control < psychotherapy and pharmacotherapy. For dropouts, psychotherapy and pharmacotherapy < control (both $\mathrm{p}<0.05$ ).

\section{COMMENTARY}

This review addresses several concerns about previous meta-analyses, including having a control condition as an internal validity check and a well-defined diagnosis of major depressive disorder (instead of including people with minor depression or subsyndromal depressive conditions). It also focuses on clinical remission, usually defined as a score on a depression scale within the normal range. There is evidence that residual depressive symptoms, even after initial response to treatment, are associated with poor psychosocial function and quality of life and higher risk of relapse, chronicity and suicide. $^{1-2}$ Many trials now report remission rates in addition to depression scores and response rates. Newer evidence-based guidelines list full remission as an objective of acute phase treatment.

Most previous meta-analyses have found no difference between psychotherapy and pharmacotherapy for reducing depression scores among people with mild to moderately severe depression. This meta-analysis reinforces that pharmacotherapy and psychotherapy are similarly effective in achieving symptom remission.

Casacalenda $e t$ al acknowledge the limitations of their review. As multi-arm studies are difficult to conduct and fund, only 6 studies were identified, all of which involved tricyclic antidepressants or a monoamine oxidase inhibitor. These medications are no longer considered first-line treatments for depression, especially of mild to moderate severity. Although previous meta-analyses have found no differences between these older medications and the newer antidepressants, those studies did not focus on remission. There is evidence that remission rates may differ across classes of the newer antidepressants. ${ }^{4}$ This may impact on comparisons with psychotherapy.

Consistent with past trials and reviews, the average remission rate of the monotherapies was about $46 \%$. While the remission rates may be higher in clinical practice, this suggests that up to half of those treated for major depressive disorder may not achieve remission with monotherapy. We need to move away from simple comparisons of psychotherapy versus pharmacotherapy to consider combined therapy. The advantages of combination treatment may be more apparent using remission as an outcome measure. There is preliminary evidence that combining antidepressant medications with psychotherapy may increase remission rates over monotherapy in severe depression ${ }^{5}$ and in chronic depression. ${ }^{6}$

In most studies, remission is defined only at a single point in time, such as at the final treatment visit. Sustained remission or recovery may be more important than the point prevalence of remission. Quality of life should also be assessed in trials since the ultimate goal of treatment is remission of symptoms and restoration of premorbid psychosocial function.

Professor Raymond W Lam, MD FRCPC Head of Division of Clinical Neuroscience Department of Psychiatry

University of British Columbia, Canada

1 Paykel ES, Ramana R, Cooper Z et al. Residual symptoms after partial remission: an important outcome in depression. Psychol Med 1995; 25: 1171-80.

2 Judd LL, Akiskal HS, Maser JD et al. Major depressive disorder: a prospective study of residual subthreshold depressive symptoms as predictor of rapid relapse. J Affect Disord. 1998; 50: $97-108$

Reesal RT, Lam RW. Clinical guidelines for the treatment of depressive disorders. II. Principles of management. Can J Pyschiatry 2001; 46: 21-8S.

4 Smith D, Dempster C, Glanville J et al. Efficacy and tolerability of venlafaxine compared with selective serotonin reuptake inhibitors and other antidepressants: a meta-analysis. $\mathrm{Br}$ IPsychiatry 2002; 180: 396-404.

5 Thase ME, Greenhouse JB, Frank E et al. Treatment of major depression with psychotherapy or psychotherapy- pharmacotherapy combinations. Arch Gen Psychiatry 1997: 54: 1009-15.

6 Keller MB, McCullough JP, Klein DN et al. A comparison of nefazodone, the cognitive behavioural-analysis system of psychotherapy, and their combination for the treatment of chronic depression. N Engl J Med 2000; 342: 1462-70. 